\title{
Tiltrotor Acoustic Data Acquisition and Analysis
}

\author{
In-flight Pressure Load Evaluation and Investigation
}

\author{
A. D. Marano ${ }^{1}{ }^{\circledR} \cdot$ T. Polito $^{1} \cdot$ M. Guida $^{1} \cdot$ M. Barbarino $^{2} \cdot$ M. Belardo $^{2} \cdot$ A. Perazzolo $^{3} \cdot$ F. Marulo $^{1}$
}

Received: 20 October 2020 / Revised: 2 January 2021 / Accepted: 23 January 2021 / Published online: 12 February 2021

(c) The Author(s) 2021

\begin{abstract}
Pressure load measurements in operative conditions represent a fundamental parameter for improving the knowledge of the in-flight forcing generation and transmission. Furthermore, it is a fundamental step for assessing the validity and confidence of numerical methods able to predict such pressure loads, usually generated by propulsion and turbulent boundary layer. The experimental in-flight measurements and analysis and the correlation with the numerical methods are activities required as a starting point for studying the transmission mechanism through the fuselage which is responsible for the vibration and noise level which can be measured inside and for identifying potential solutions for their mitigation. The in-flight measurements have been carried out on a Leonardo Helicopter tiltrotor with the main goals to perform the validation of an experimental setup in a fully new environment and the assessment of a data analysis procedure according to the objectives of the Clean Sky 2 Fast Rotorcraft Project T-WING (CS2, Clean Sky 2 joint undertaking third amended bi-annual work plan and budget, 2018-2019).
\end{abstract}

Keywords Flight test $\cdot$ Tiltrotor noise measurement $\cdot$ Analysis of in-flight acoustic data

\section{Introduction}

In the last few years, for a fast and reliable point to point connection or intercity flights and to improve public mobility and access to air transportation, the Runway-Independent Aircraft concept is progressively becoming more prominent in civil aviation. Moreover, the market prospects predict an increasing demand of Tiltrotors for business flights, air medical, search and rescue applications [1]. In order for such vehicles to be working successfully and commercially viable, the interior noise levels must be acceptable to civil passengers. Noise is the result of propulsion systems, interaction between high-speed air flow and aircraft surfaces and

A. D. Marano

aniellodaniele.marano@unina.it

1 Department of Industrial Engineering, UniNa-University Federico II, Via Claudio, 21, 80125 Naples, Italy

2 CIRA-Italian Aerospace Research Center, Via Maiorise, 81043 Capua, Italy

3 Leonardo Helicopters, Via Giovanni Agusta, 520, 21017 Samarate, Italy internal operation systems [2]. The noise is an important design and operation parameter of every aircraft because the effects of too intense levels can affect the crew and passengers comfort and pose problems for on-board equipment and communication systems [3, 4]. Structural-acoustic measurements were taken aboard an existing tiltrotor aircraft to better investigate the physical mechanisms that originate the interior noise in the tiltrotor. Although the flight test measurements also include structural accelerations and internal noise, the results presented in this paper focus on the exterior pressure loading on the fuselage $[5,6]$. This paper is more addressed to the experimental in-flight measurements and analysis, while a companion paper will be dedicated to the numerical methods [7] and their correlation with the experimental measurements [8]. Both these activities are required as a starting point for studying the transmission mechanism through the fuselage which is responsible for the vibration and noise level which can be measured inside and for identifying potential solutions for their mitigation [9]. The Knowledge of external pressure loads in flight is also required to replicate the flight conditions in a laboratory to test different solutions for improvement passenger comfort and identify the most promising ones [10]. The in-flight measurements 
have been first carried out on a flying Leonardo Helicopter tiltrotor, undergoing certification for use in the civil sphere. The scientific literature concerning this flight vehicle is very reduced. An important point of reference is certainly the analysis of the XV-15 acoustic data performed by the Vehicle Technology Center of the NASA Langley Research Center [11]. The sources that induce pressure loads on the external fuselage of the tiltrotor are essentially of two types: a rotor noise due to the presence of the large rotors located at the wingtips and the boundary layer noise. The acoustic loads produced by the propeller is mostly affected by the power produced, forward and rotational tip speeds, number of blades, blade shape and thickness and distance from the propeller. Propeller engines generate a noise field that is highly tonal in frequency content and highly directional in spatial distribution [12-14]. In high-speed flight, boundary layer noise can be a significant part of the noise perceived in the cabin. The obtained results are interesting and promising: these measurement procedures could also be addressed to more traditional airplanes and, possibly, to ground vehicles for characterizing, from this point of view, different transport systems.

\section{Flight Test Set-up}

Measurement and Analysis of noise is a powerful diagnostic tool in noise reduction for improving the quality of flights and to maximise passengers' comfort on board [15]. The Tiltorotor under test is able to take few seconds to complete the conversation from helicopter mode to aeroplane mode but, in general, there is no need to rush to complete the conversion since the airspeed and climb rate achieved in airplane and VTOL/conversion mode overlap for some time during a standard departure profile. The maximum altitude at which the tiltrotor can reach in VTOL/Conversion mode when moving and hovering is around $8,000 \mathrm{ft}$ according to gross weight whereas the usual and maximum cruising altitude is around $20,000 \mathrm{ft}$ up to a maximum of $25,000 \mathrm{ft}$. The interest of the tests was mainly focused on altitude, usual and cruising speeds for this reason the conversion phase was not taken into consideration for the acquisition of the noise data. Noise data were acquired at the nine flight conditions indicated in Table 1. The interest of the tests was also to study propeller noise and turbulent boundary layer effects rather than those related to turbine and compressor noise, which should be at
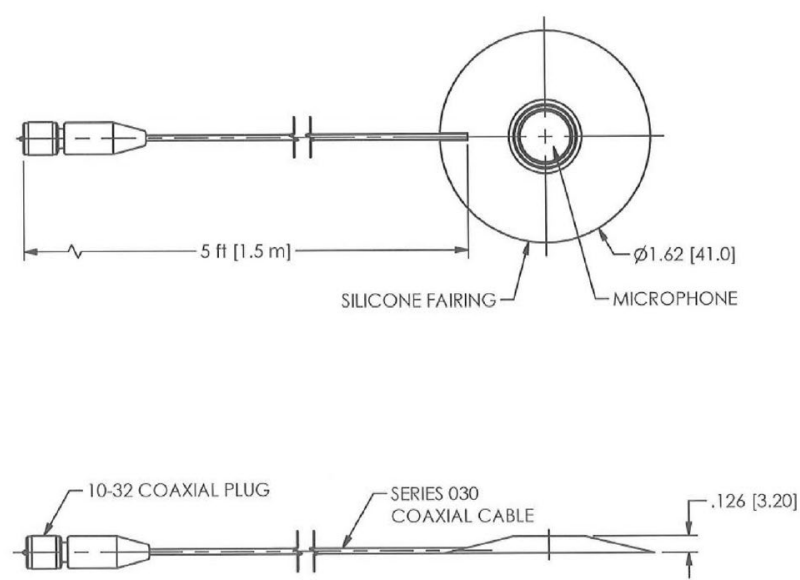

Fig. 1 Surface microphone size

higher frequencies. The graphs in this article refer to lower frequency values. For a light twin-engine aircraft, for example, the cabin noise spectrum typically has an engine tone at around $700 \mathrm{~Hz}$. On the other side, structure-borne noise (SBN) can be a major contributor to the SPL in the cabin of a helicopter. For example, an investigation of the noise sources contributing to the acoustic environment in an eightseat helicopter showed indicated that SBN from the engine and gearbox dominated cabin sound levels at frequencies above about $3000 \mathrm{~Hz}$. The fundamental tonal component of compressor and turbine could be appreciated in the cabin sounds level graph but not in the exterior noise because the nature of SBN linked to this source. Some components of the interior acoustic field are the result of mechanical forces acting on distant regions of the airframe. The resulting vibrational energy is transmitted through the structure and then radiated into the fuselage interior as noise [12]. The external acoustic measurements and analysis carried out on board of the tiltrotor also show that the acoustic radiation from the engine inlet did not generate sufficiently high sound pressure levels to be dominant source and the broadband SBN has not been identified, probably because of masking by broadband airborne noise. As regards the test set up, the exterior spectrum levels were measured applying twelve surface pressure transducers (Fig. 1) with $13 \mathrm{~mm}$ diameter diaphragms and $3 \mathrm{~mm}$ height on the fuselage: eleven microphones on the port side of the tiltrotor and one surface microphone (no. 12) on the right side to verify the symmetry of the results. The exterior sensors installation scheme is shown in Fig. 2.

Table 1 Flight test conditions

\begin{tabular}{|c|c|c|c|c|c|c|c|c|c|}
\hline & I & II & III & IV & V & VI & VII & VIII & IX \\
\hline Speed (kt) & 150 & 155 & 160 & 165 & 170 & 175 & 180 & 185 & 190 \\
\hline Altitude (ft) & 20,000 & 20,000 & 20,000 & 20,000 & 20,000 & 20,000 & 20,000 & 20,000 & 20,000 \\
\hline RPM & 478 & 478 & 478 & 478 & 478 & 478 & 478 & 478 & 478 \\
\hline
\end{tabular}




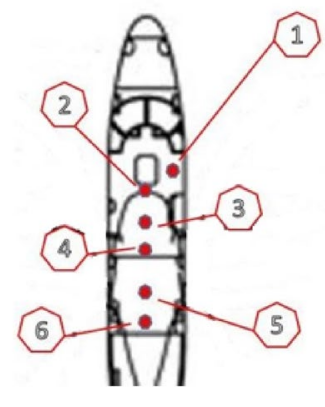

(a)

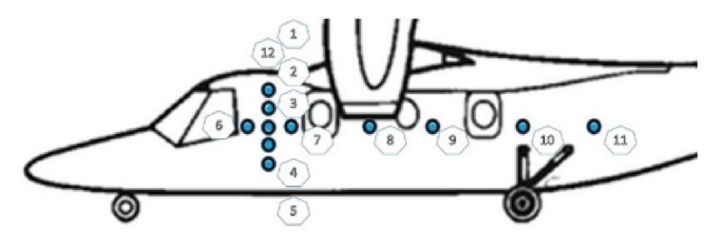

(b)

Fig. 2 Layout diagram of the internal (a) and external (b) microphones

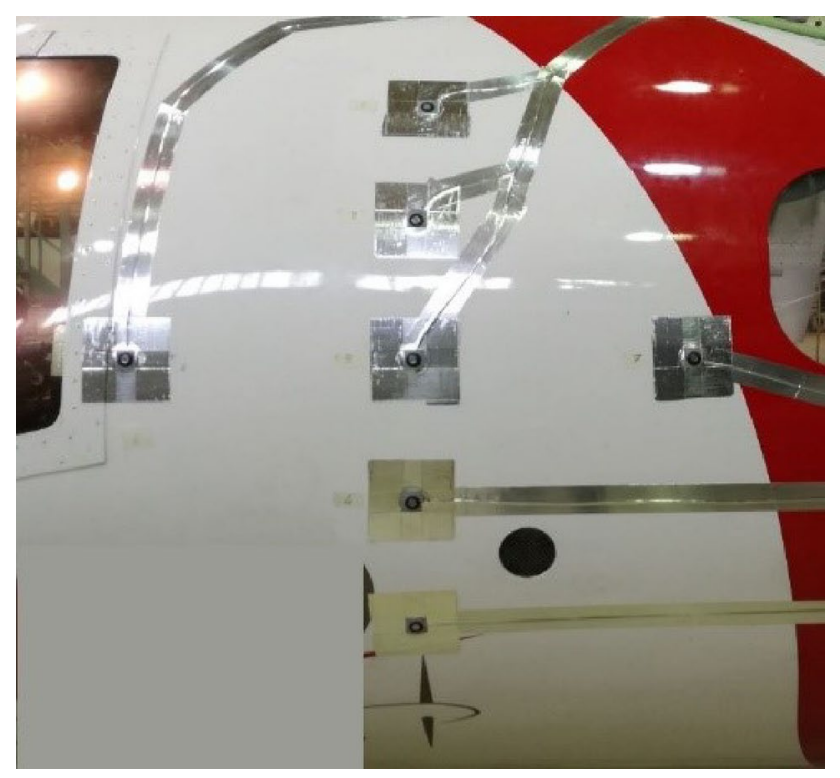

Fig. 3 Photograph of Exterior Sensors Locations

Since the pressure loads are much higher near the plane of rotation of the propeller and rapidly decrease both forward and aft, most of the sensors have been installed to form a ' $\mathrm{T}$ ' as close as possible to the propeller disk when the tiltrotor is in airplane configuration. This arrangement was able to take into consideration both longitudinal and transverse variations in the distribution of acoustic loads. The Fig. 3 shows the surface pressure transducers locations. The main purpose of the work was the experimental acquisition of external acoustic loads acting on the tiltrotor fuselage to carry on a comparison with the numerical results provided by noise prediction tools. However, during flight tests, in addition to acquisitions of external pressures, structural accelerations and internal pressure levels of the fuselage were acquired. Accelerations were measured on the inside of the skin at six locations far from shell and vibrating panels and as close as possible to the fuselage frames and stiffeners. Piezoelectric accelerometers with a nominal sensitivity of $10 \mathrm{mV} / \mathrm{g}$ were used. Interior pressures at six locations were measured using half-inch condenser microphones of random incidence type with a nominal sensitivity of $50 \mathrm{mV} / \mathrm{Pa}$. $30 \mathrm{sec}$ of data were acquired.

\section{Test Results}

\subsection{Time Domain Results}

The acquired data were analyzed through DNA: a dedicated MATLAB code able to plot the TestLab Spectral Testing results stored in a mat file and developed by LIght saFe quiEt - Laboratory, UniNa. DNA is short for Data Noise Analyzer. This tool was validated by means a careful comparison with the results obtained through the commercial software. During Flight Test the external surface microphone no. 11 did not work correctly. This anomaly could be due to an electrical problem. The plot related to this microphone showed very "wired" peaks, so it was decided to exclude it from the data process. However, the number of sensors adopted was enough to perform an excellent acquisition and analysis of the data and to output some fundamental conclusions about the noise. The noise distribution pattern can be expected to be broader for larger propeller diameter and for greater clearance between the propeller and the fuselage of the Tiltrotor. In addition, the directional characteristics may be affected by operational factors such as flight speed, by interactions with the fuselage flow field, and by interaction with a second propeller in a counter-rotating configuration. The values and graphs shown in this report are mainly related to flight condition VI. The measured pressure fluctuations and noise levels are quantified from a subjective point of view by means the Overall Sound Pressure Level (OASPL) [5] and [13]. The Fig. 4 shows the OASPL plotted as a function of the flight speeds, with the twelve microphones indicated by different symbols. The OASPL is highest near the plane of rotation of the propeller and decreases rapidly in both forward and aft directions. As expected the overall level shows a linear trend with the speed. It significantly increases when the flight speed increases. It is interesting to note for condition IX at high flight speed, due to the increase of the aerodynamic noise, the OASPL of the microphone 11, located downstream of the wing, is comparable with the value relative to the microphone 6 , near the cockpit. Focusing of microphones 1, 3 and 5 it is possible to 


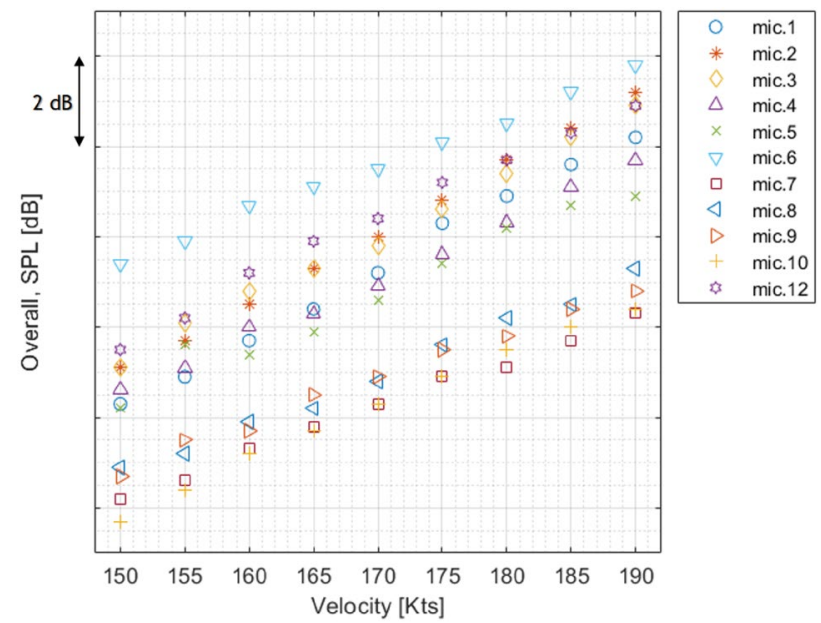

Fig. 4 OASPL at different flight conditions

observe that in the circumferential direction the noise level decreases. Sample time histories for the surface microphone no. 6 at the different flight speeds are shown in Fig. 5 in which the time period represents one rotation of the propeller. In each subplot the thin line represents the instantaneous response whereas the heavy line denotes the time averaged response. The time averaged response closely follows the instantaneous response and you can appreciate that the magnitude of the response changes quite whereas the shape of the time history doesn't vary significantly as a function of the flight speed: the periodic trend linked to the passage of the propeller blades is very clear.

\subsection{Frequency Domain Results}

Fig. 6 shows the spectral shape for each microphone at the cruise speed of the tilrotor. In general, the harmonic peaks of the exterior pressures due to the rotating propeller approaches the broadband noise floor between 300 and $400 \mathrm{~Hz}$. By observing the data of the microphones 8, 9 and 10 , located under the wing, we note that only the first three harmonics of the fundamental blade passage frequency (BPF) are greater than the broadband noise. The presence of the wing considerably disrupts the flow and it probably increases the broadband level. The symmetry condition can be verified from the autospectra plots related to microphones 3 and 12 in Fig. 7. Figure 11 shows the noise spectra taking into account the external microphones respectively in
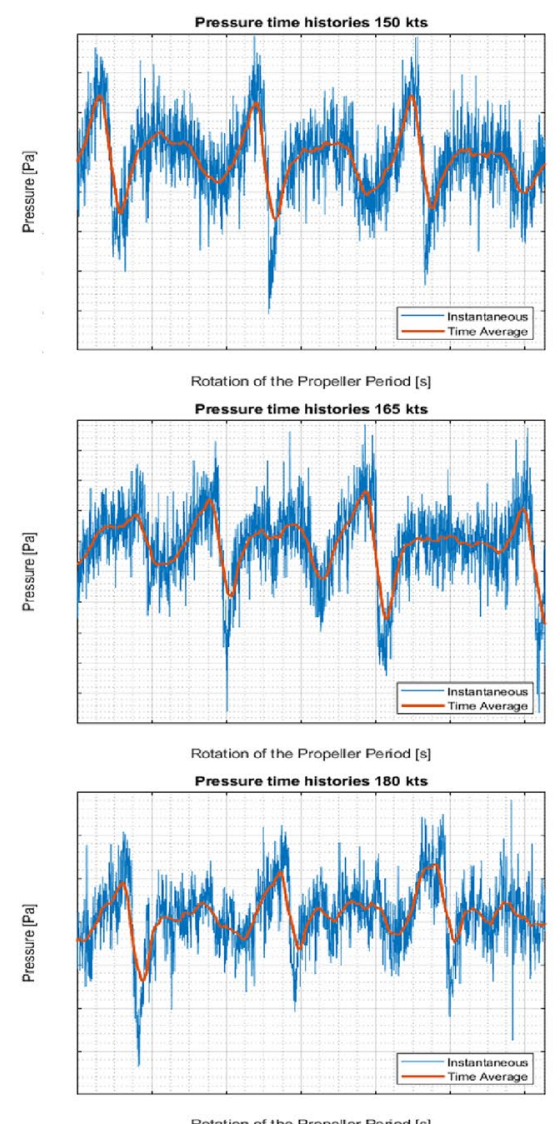

Rotation of the Propeller Period [s]
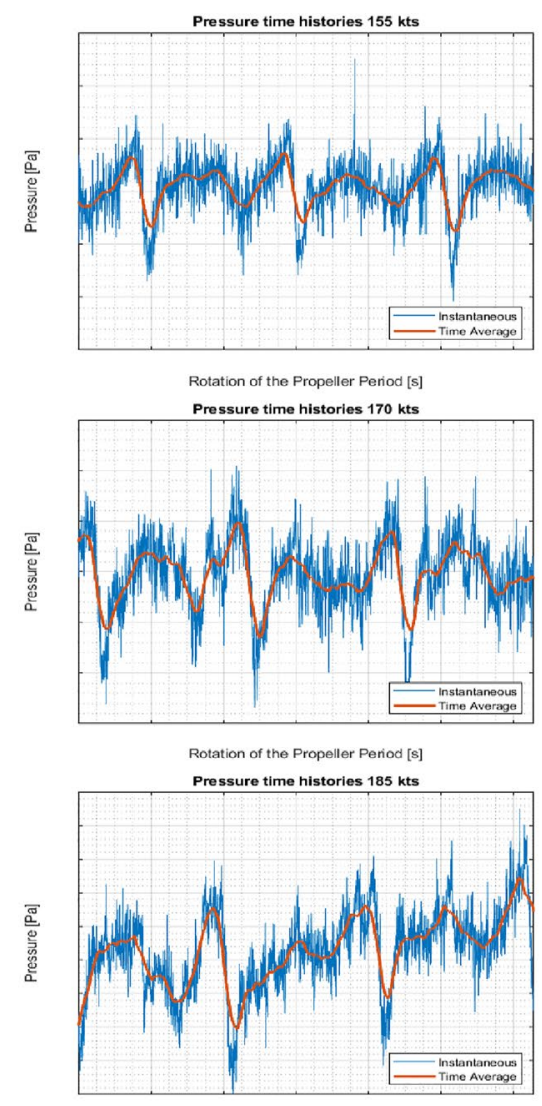

Rotation of the Propeler Period [s]

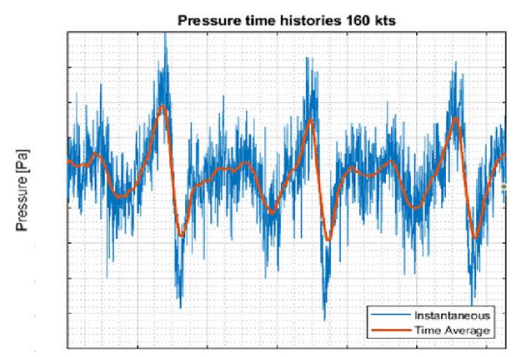

Rotation of the Propeller Period [s]
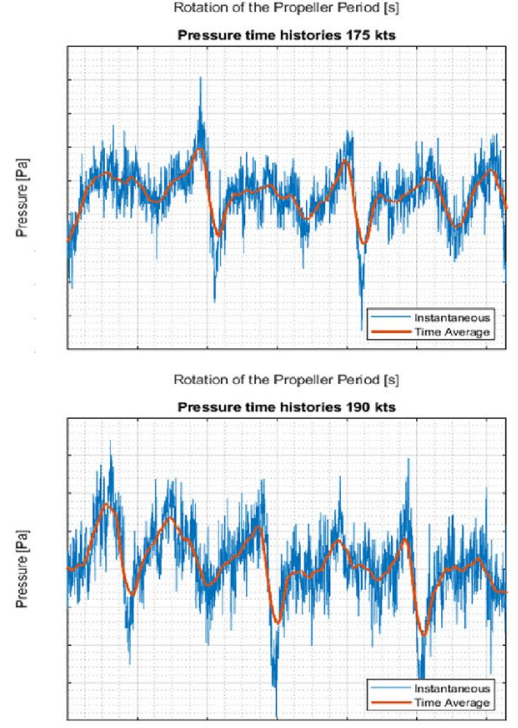

Rotation of the Propeller Period [s]

Fig. 5 Acoustic pressures time histories 

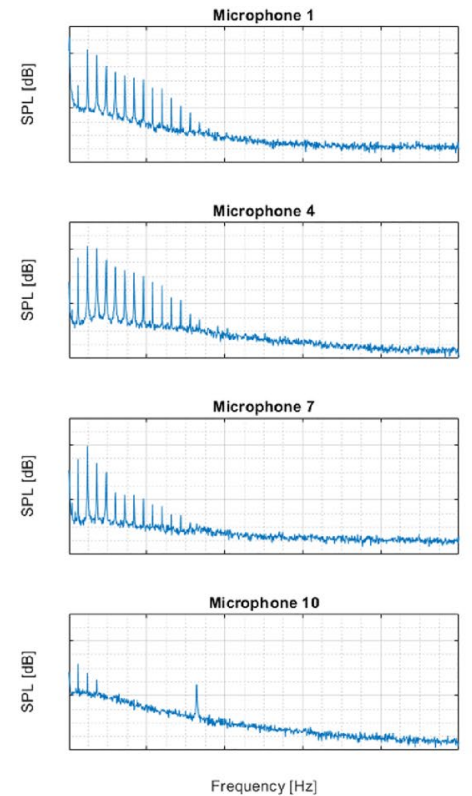
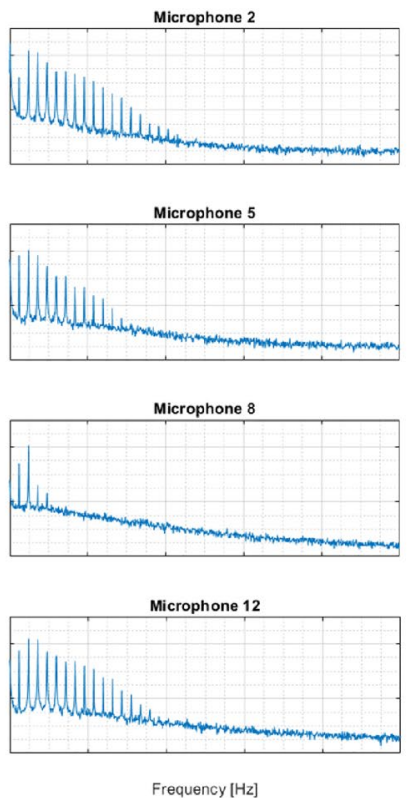
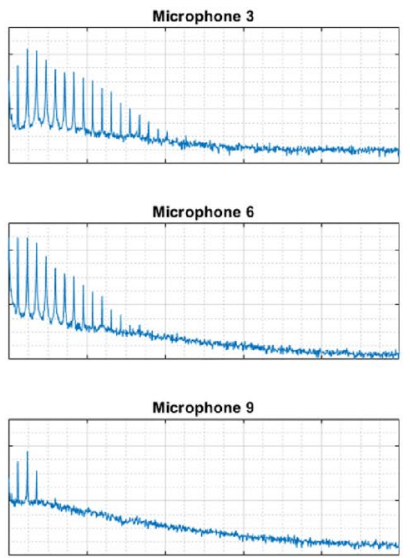

Fig. 6 SPL Spectral shape for each external microphone, $175 \mathrm{kts}$

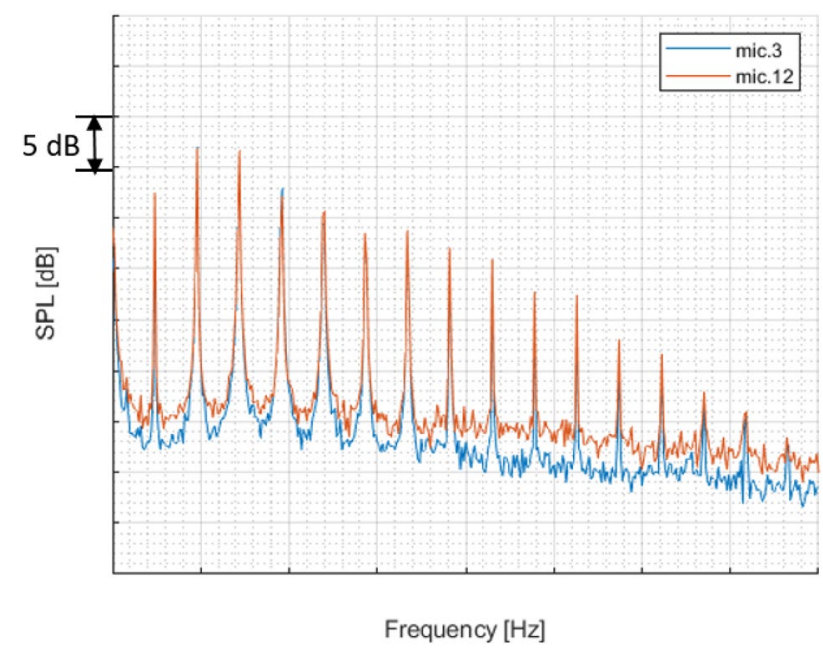

Fig. 7 Noise spectrum-symmetry condition, 175 kts

the longitudinal and transverse directions with respect to the fuselage. It is clear that the tone at the first blade-passage frequency has the highest level and succeeding tones decrease at a rate of about $2 \mathrm{~dB}$ per harmonic. BPF fall in the low frequency range up to around $350 \mathrm{~Hz}$ whereas the boundary layer noise is dominant at the higher frequency. Fig. 8 illustrates sound spectrum of the external microphone no. 3 in the $1 / 3$ octave band frequency for the whole speed range, with the frequency axis in logarithmic scale. The trend of the signal in $1 / 3$ octave tends to increase the sound levels at the higher frequency and to attenuate them at lower ones, thus better representing human hearing. The different characteristics of the noise can have important effects on the noise transmitted through the fuselage. The fuselage noise reduction is shown in Fig. 9 as the difference between the exterior overall SPL on the fuselage surface and the overall SPL transmitted through to the interior, for different flight speeds. Figure 10 shows a comparison of the noise levels acquired simultaneously by the two microphones, respectively external (above) and internal (below), located in the fuselage section near the pilot's head. The levels in the cabin are significantly lower than the levels on the exterior. indicating that the sidewall provides substantial noise reduction. By focusing on the internal noise spectrum, some effects of sidewall transmission characteristics are evident in the measured cabin noise. Both the propeller tones and the boundary layer noise appear in the cabin with the propeller harmonics dominating, as they do in the exterior noise. Moreover, both the propeller tones and the boundary layer noise levels inside the cabin vary in an irregular manner with frequency, in contrast to the smoother variations showed by the exterior noise levels. This frequency-dependent behaviour is probably associated with fuselage shell, panel modal activity and various experimental instruments on board the tiltrotor under test.

Figures 12, 13 and 14 refer to the analysis of the signal in the frequency domain and in particular to the use of Power Spectral Density (PSD). This type of function allows to evaluate the distribution of power in the acoustic signal with respect to frequency by identifying and quantifying oscillatory components. The graph 13 shows the shape of the signal obtained by applying the Welch's Method. By applying this method and by overlapping 

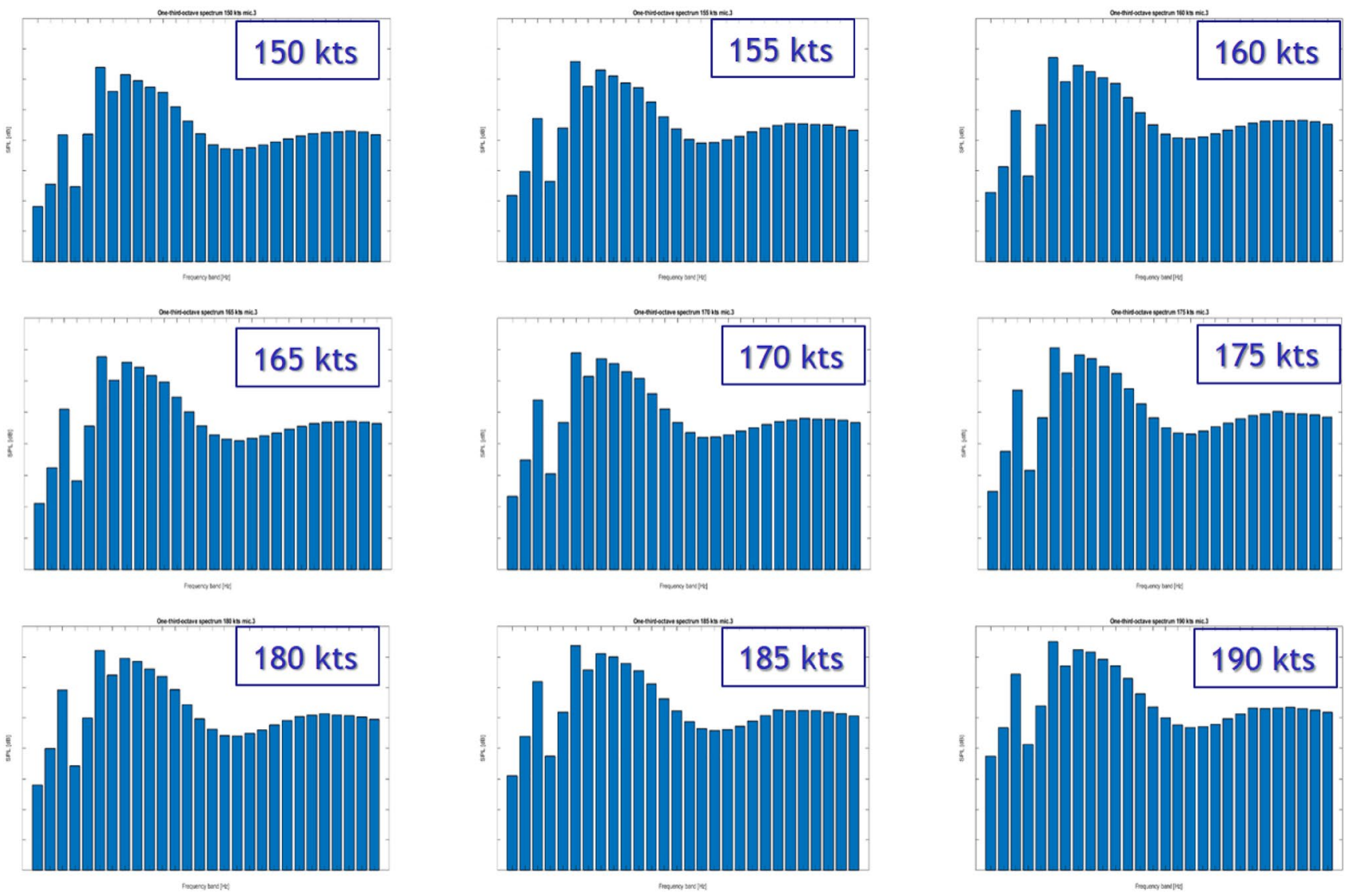

Fig. 8 SPL 1/3 octave band frequency, mic.3

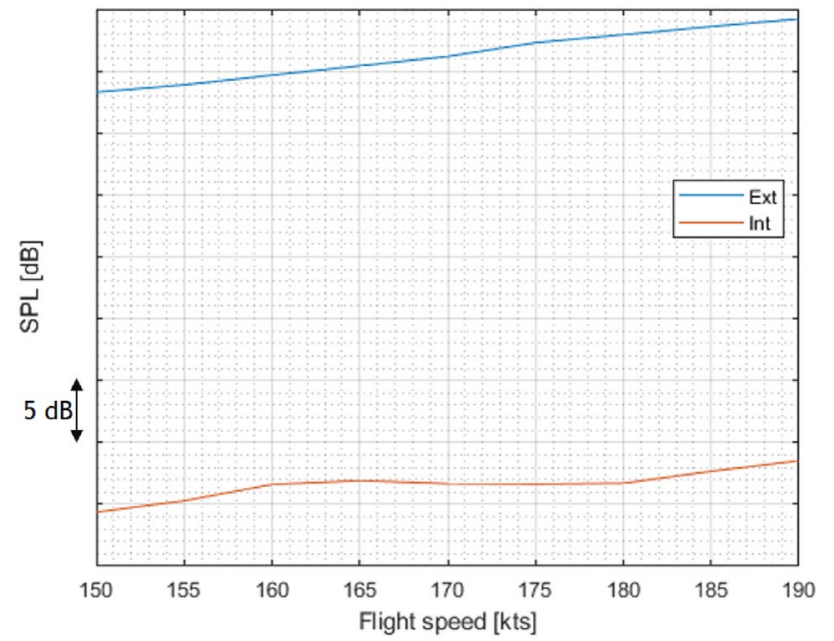

Fig. 9 OASPL for increasing flight speed. Comparison between external mic. 1 and internal mic. 1

the signal it is possible to reduce the spectral variance of the measurements. The time interval of the measure or a subinterval of interest, is divided into $\mathrm{k}$ equal-length section to which a window is applied. Then the Fast

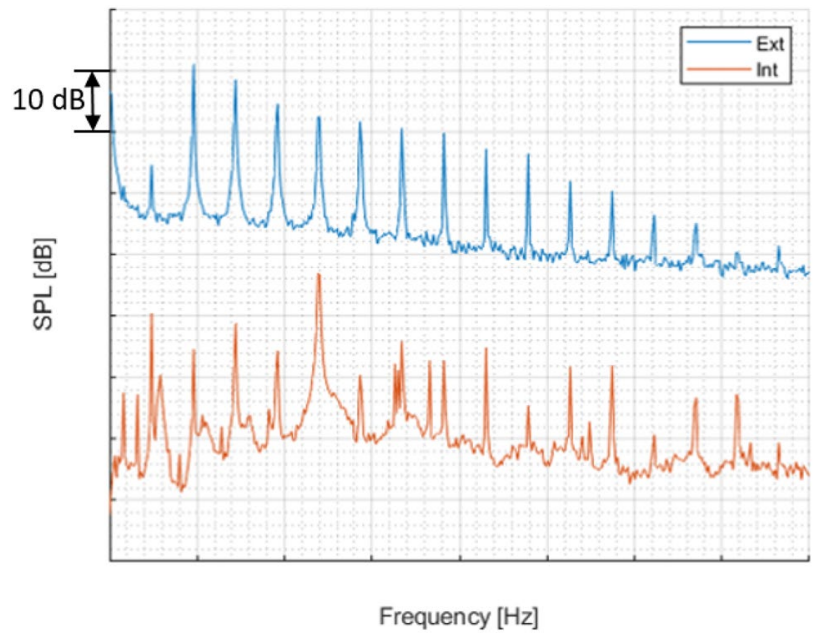

Fig. 10 Noise spectrum-comparison between external mic. 1 and internal mic. $1,175 \mathrm{kts}$

Frequency Transform (FFT) of each section is computed and an array of $\mathrm{k}$ signal segments in the frequency domain is obtained. Finally, by dividing by $\mathrm{k}$ and applying an appropriate scale factor, an improved estimate of the PSD 

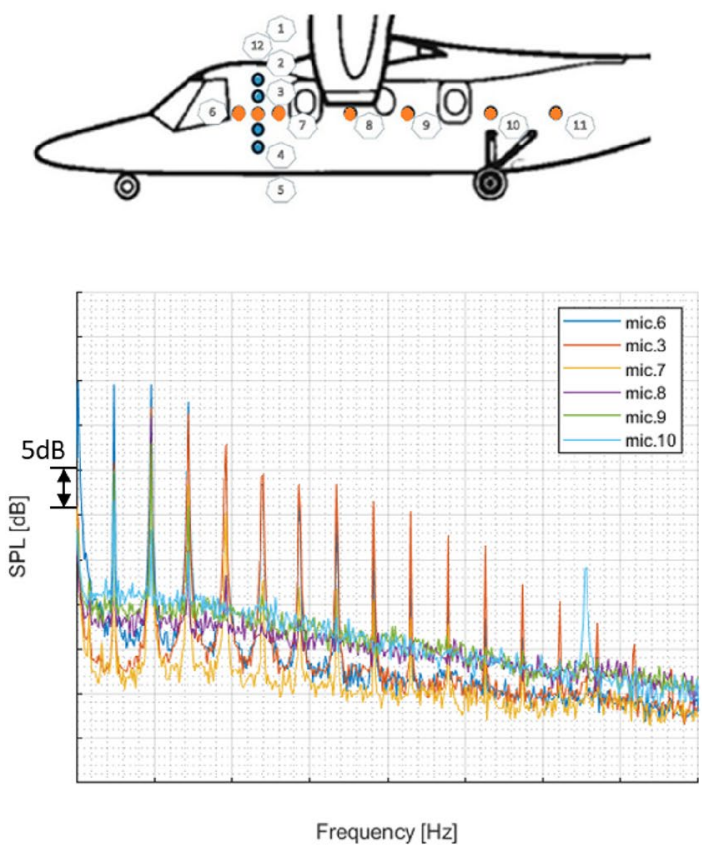
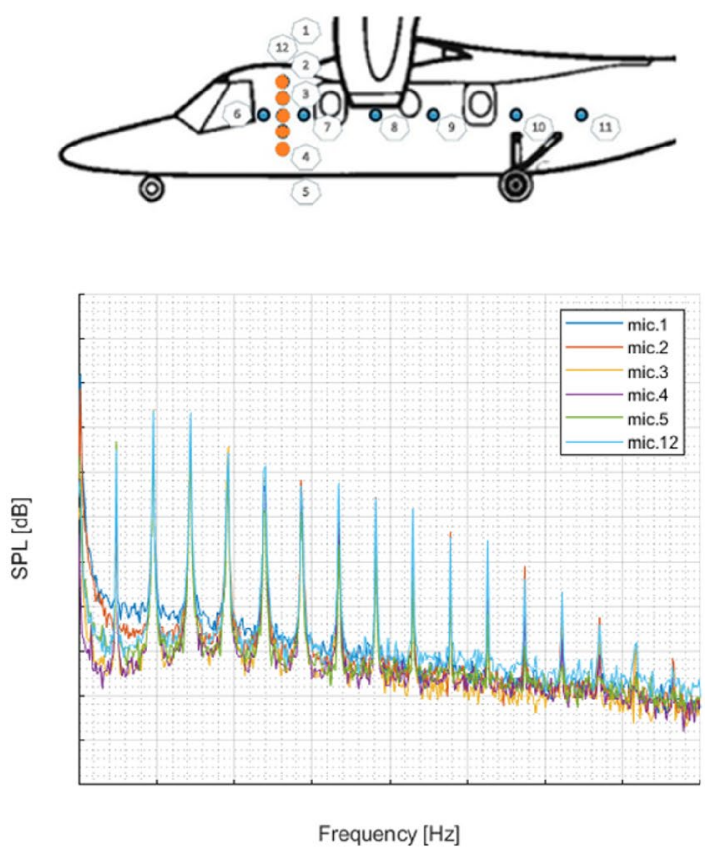

Fig. 11 Noise spectrum-longitudinal and circumferential noise distributions, 175 kts

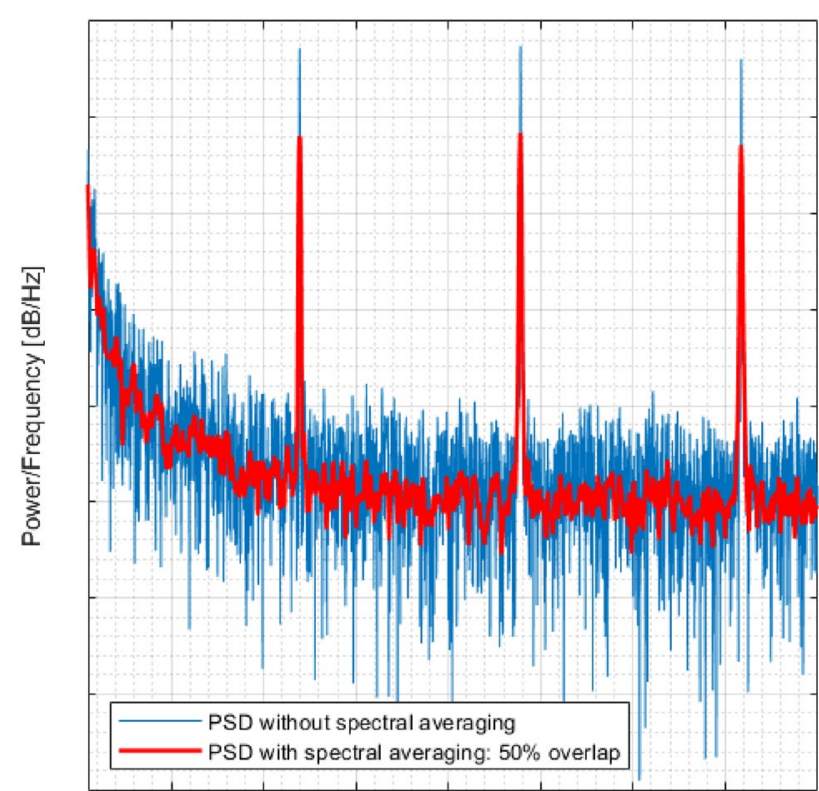

Frequency $[\mathrm{Hz}]$

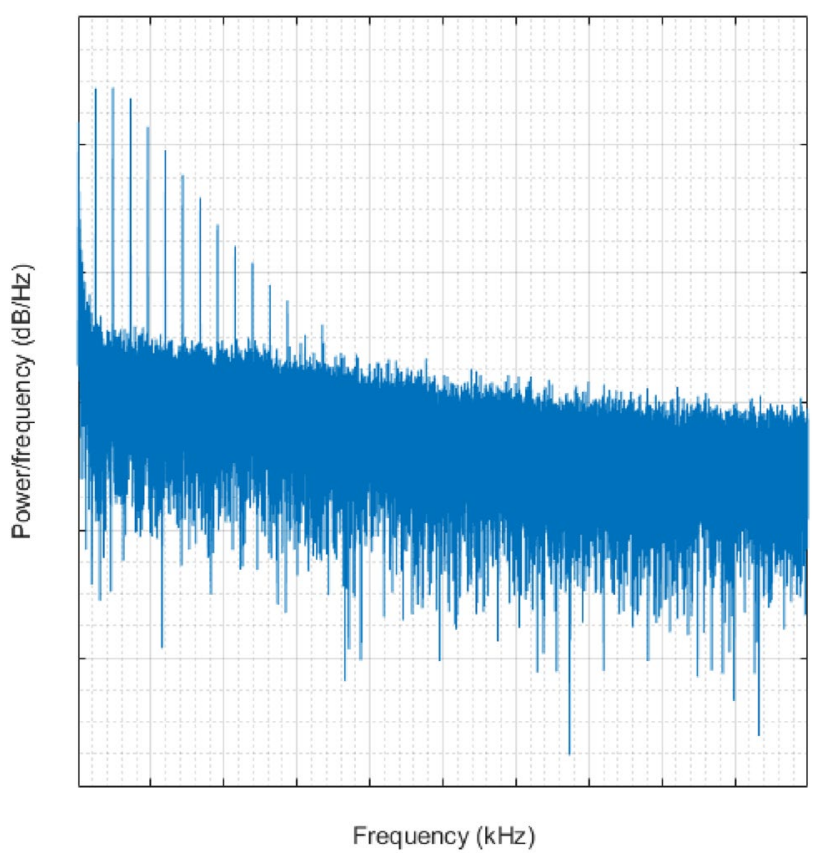

Fig. 13 PSD Welch's (periodogram) method

below a given frequency to the overall RMS pressure level for the time frame of interest. In other terms it highlights, how different portions of the noise spectrum contribute to the overall RMS noise level, in a quantitative manner:

- steep slopes indicate relatively strong narrowband disturbance 

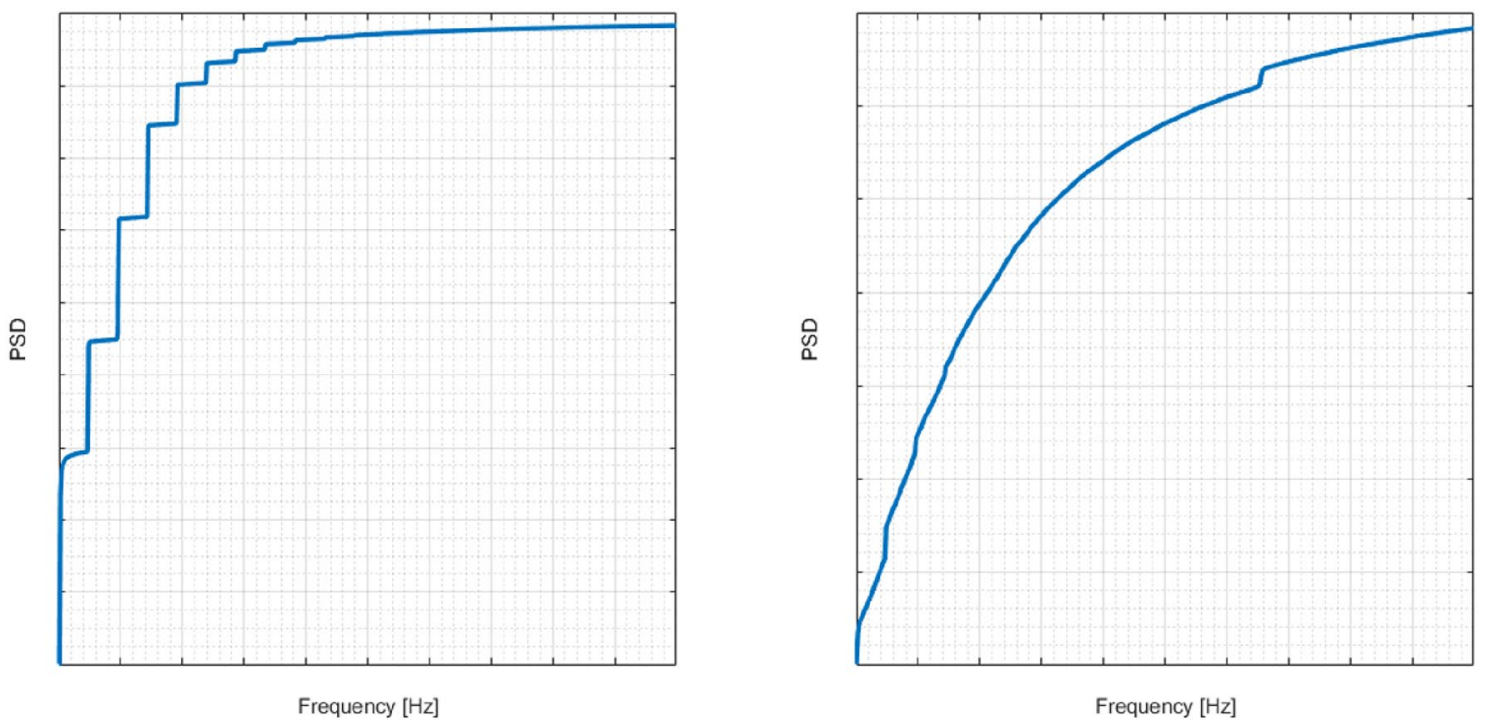

Fig. 14 Cumulative distribution root mean square vs frequency, mic.6 (left) and mic.10 (right), 175 kts

- shallow slopes indicate relatively quiet, broadband portions of the spectrum

The first eight peaks of the figure on the left are representative of the contributions provided by the various tones due to the passage of the propeller blades. The magnitude of each step decreases with increasing frequency and, no longer providing appreciable contributions, the curve flattens starting from $350 \mathrm{~Hz}$. The figure on the right is related to the microphone 10 located in the fuselage section downstream of the wing where the tonal components of the noise are covered by the contribution of the Turbolent Boundary Layer (TBL) [10].

\section{Statistics and Confidence Intervals}

Figure 15 shows a distribution of the number of samples of the measurements and the SPL values in $\mathrm{dB}$. The figure can be interpreted as a quality indicator about the number of samples acquired: histograms become smoother and more continuous when they are made from an increasing number of samples. In the limit when the number of samples is infinite, the resulting curve is a probability density function. The data acquired during the whole acquisition time, referring to a time equal to the propeller rotation period $(0.126 \mathrm{sec}$.), are shown in Fig. 16. This plot shows that with increasing speed there is a greater dispersion of the measurement: the data are less focused. Confidence intervals are an approach to impart a range of values that contains the test outcome with a degree of certainty given by the confidence level. The confidence

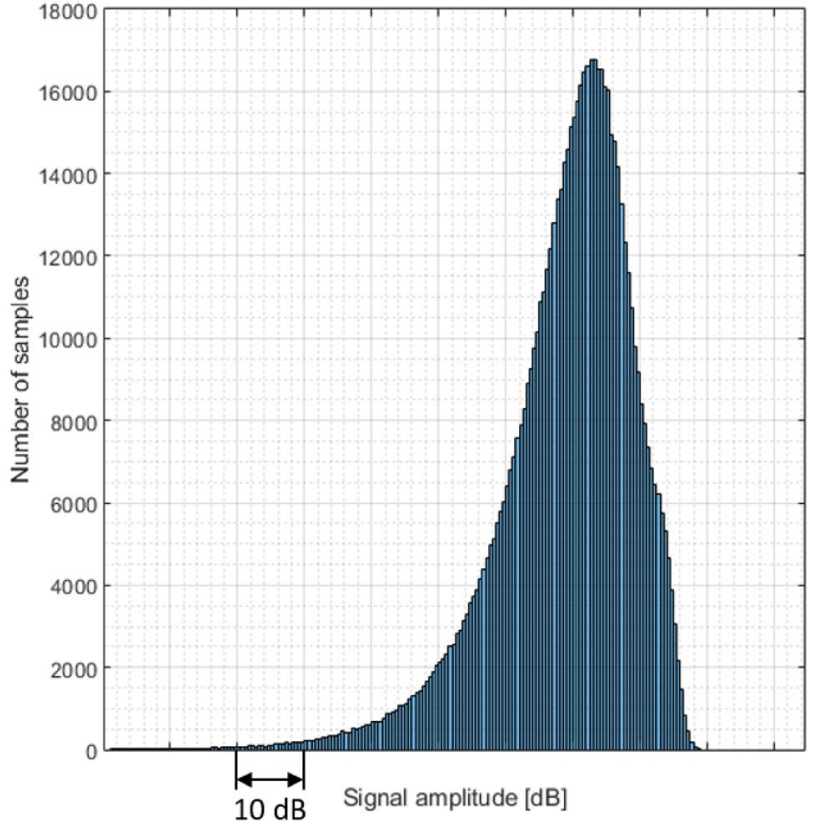

Fig. 15 Probability distribution of the signal

level clearly defines the range of probable values and the risk of an incorrect conclusion. The general expression of confidence intervals is:

Estimate \pm Margin of error

All values in the confidence interval have equal probability of being the true, sought-after value of the population [21]. The confidence interval will shrink as the sample 

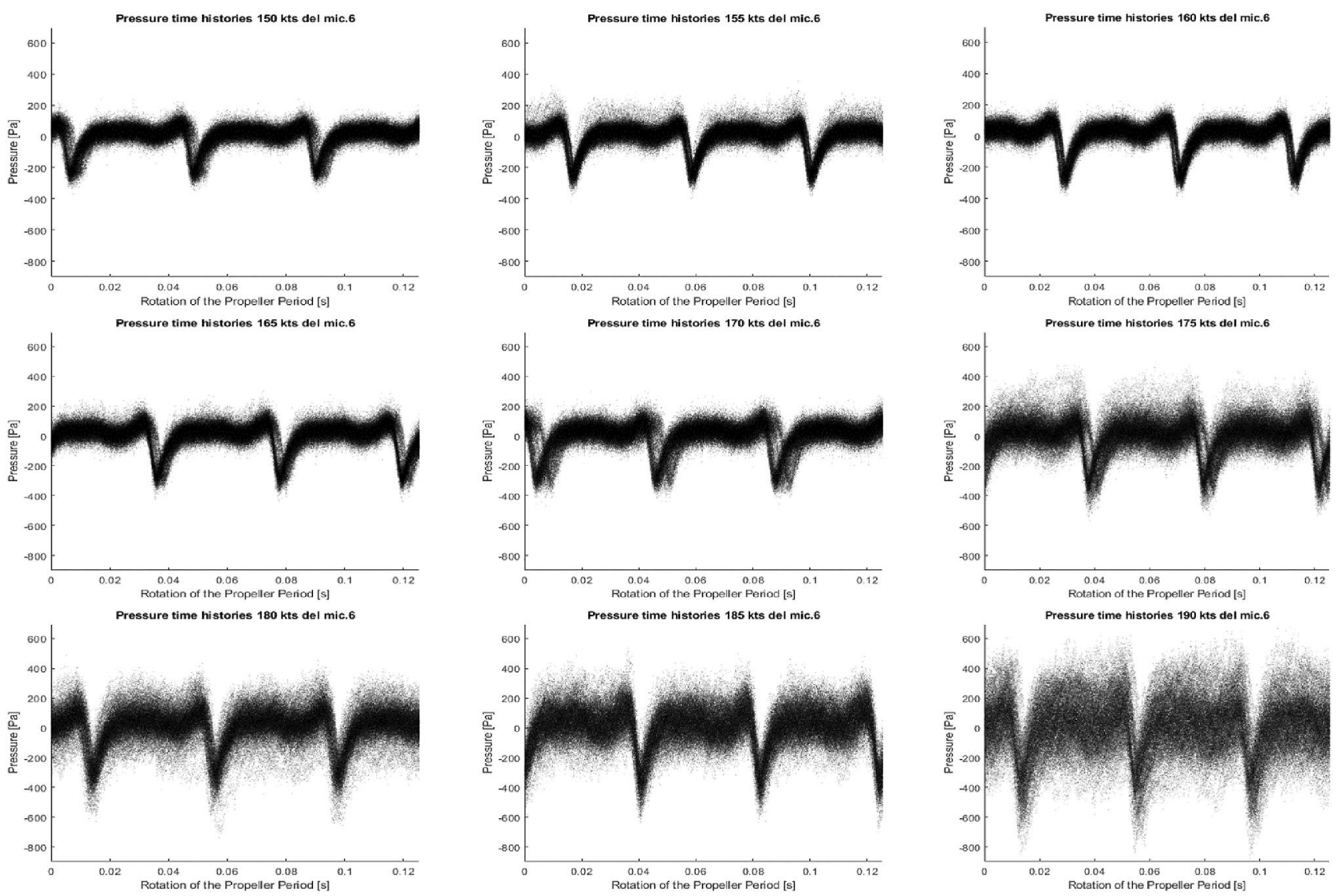

Fig. 16 Pressure time history refer to propeller rotation period, mic. 6
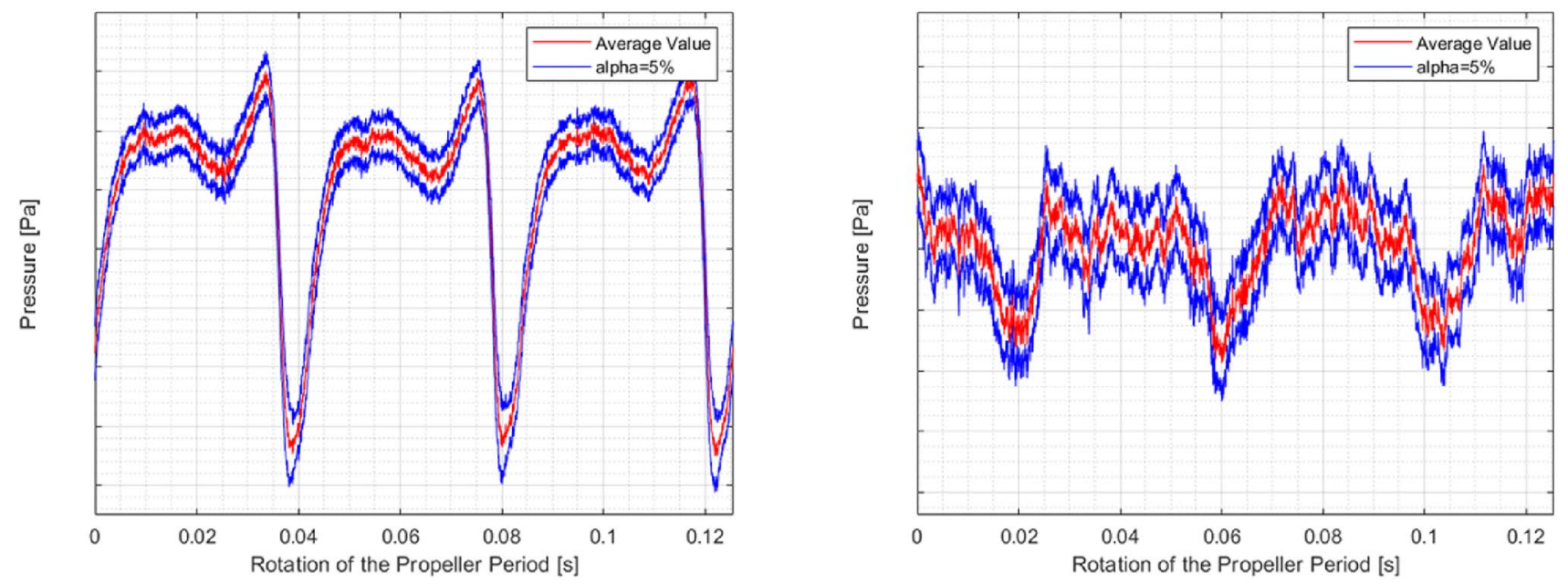

Fig. 17 Averaged value and confidential interval, external mic. 6 (left) and mic.10 (right), 175 kts

size increases, all else being equal. Figure 17 shows the confidence intervals of microphones 6 and 10 respectively. The blue lines represent an estimated range of values which with a probability of $95 \%$ will include the average value of the measurements (red line). The estimated range was calculated from a series of around 2500 sample data. A higher confidence level will tend to widen the confidence level given a fixed sample size, as it can be seen through the Figs. 18, 19, 20, 21, 22, 23. The graphs show the trend of the signal average and the relative confidence 
Fig. 18 Confidence intervals time domain - mic.6, $150 \mathrm{kts}$

Fig. 19 Confidence intervals time domain - mic.6, $175 \mathrm{kts}$

Fig. 20 Confidence intervals time domain - mic.6, $190 \mathrm{kts}$
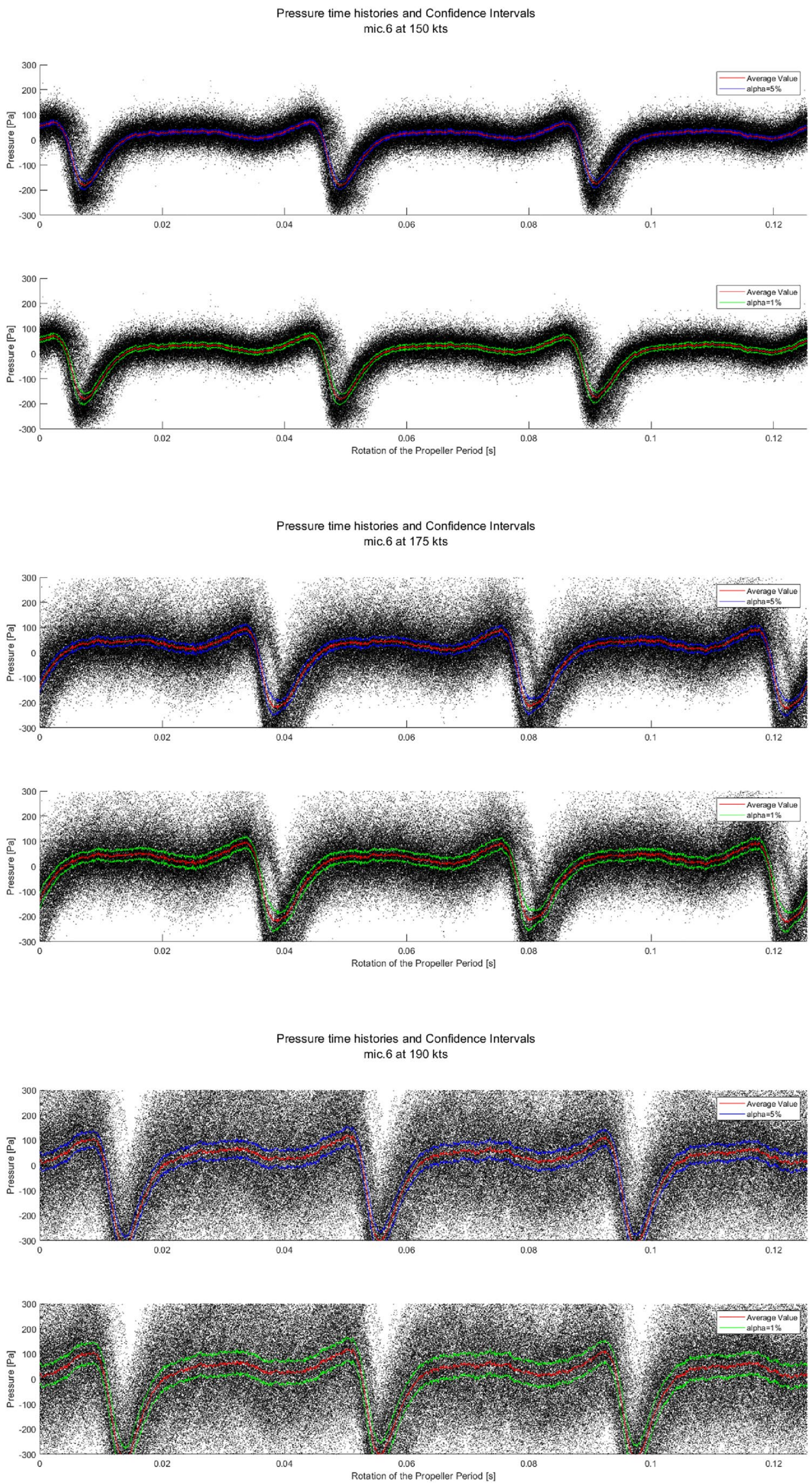
Fig. 21 Confidence intervals time domain - mic.10, $150 \mathrm{kts}$

Fig. 22 Confidence intervals time domain - mic.10, $175 \mathrm{kts}$

Fig. 23 Confidence intervals time domain - mic.10, $190 \mathrm{kts}$
Pressure time histories and Confidence Intervals mic. 10 at $150 \mathrm{kts}$
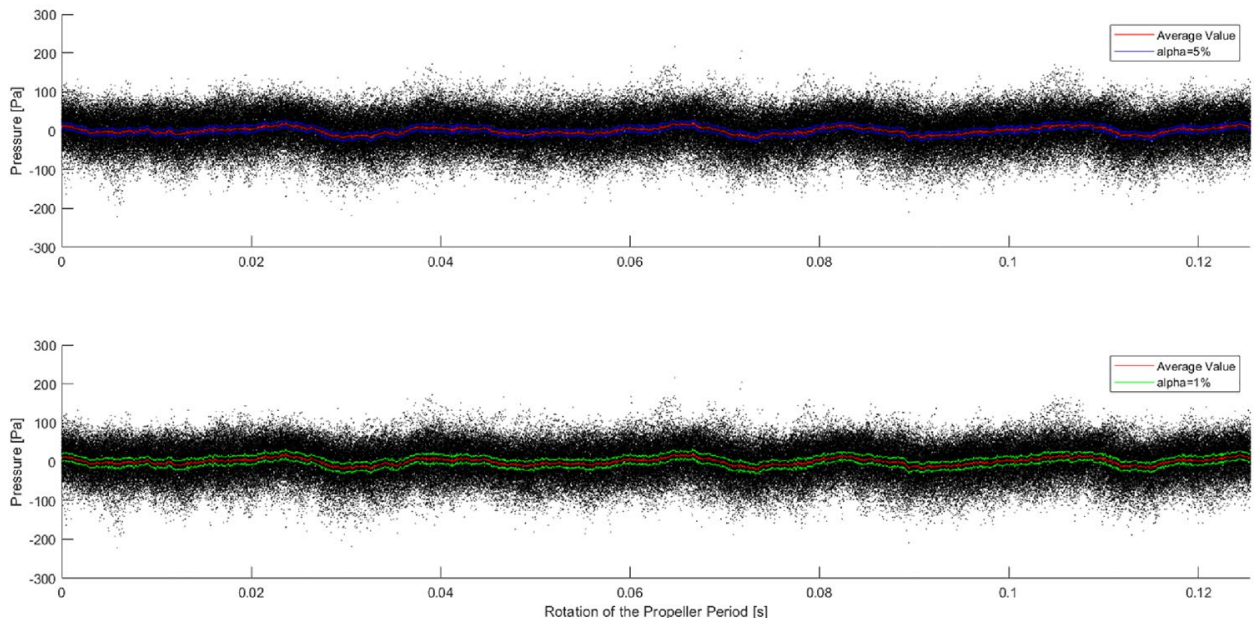

Pressure time histories and Confidence Intervals mic. 10 at $175 \mathrm{kts}$
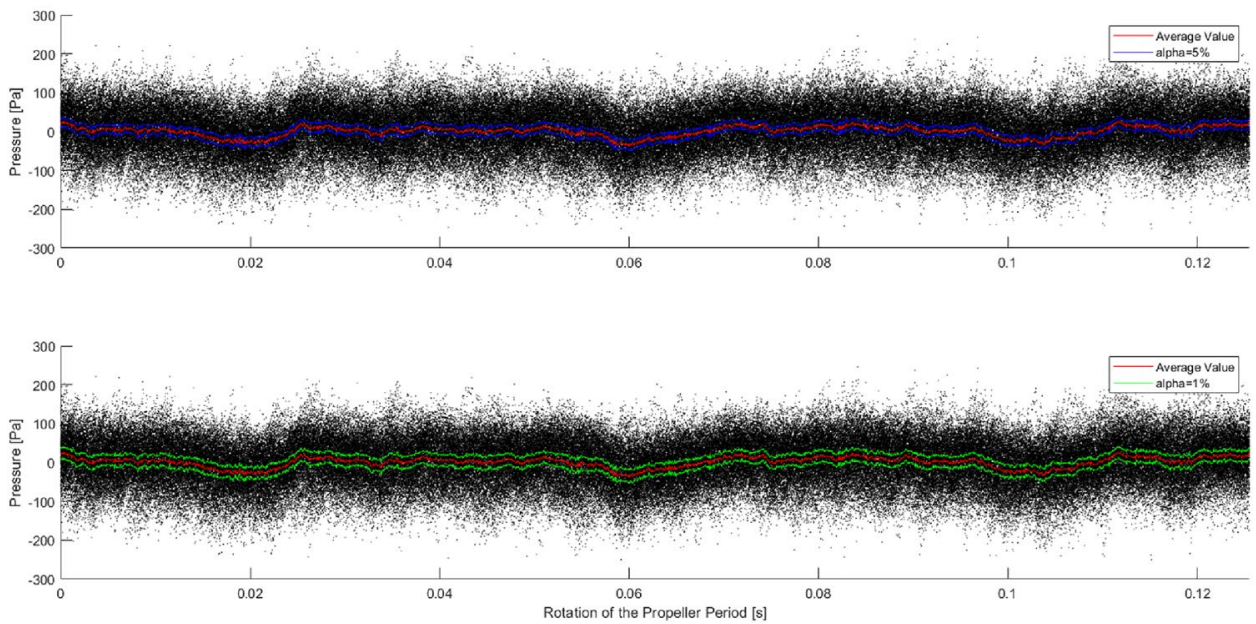

Pressure time histories and Confidence Intervals mic. 10 at $190 \mathrm{kts}$
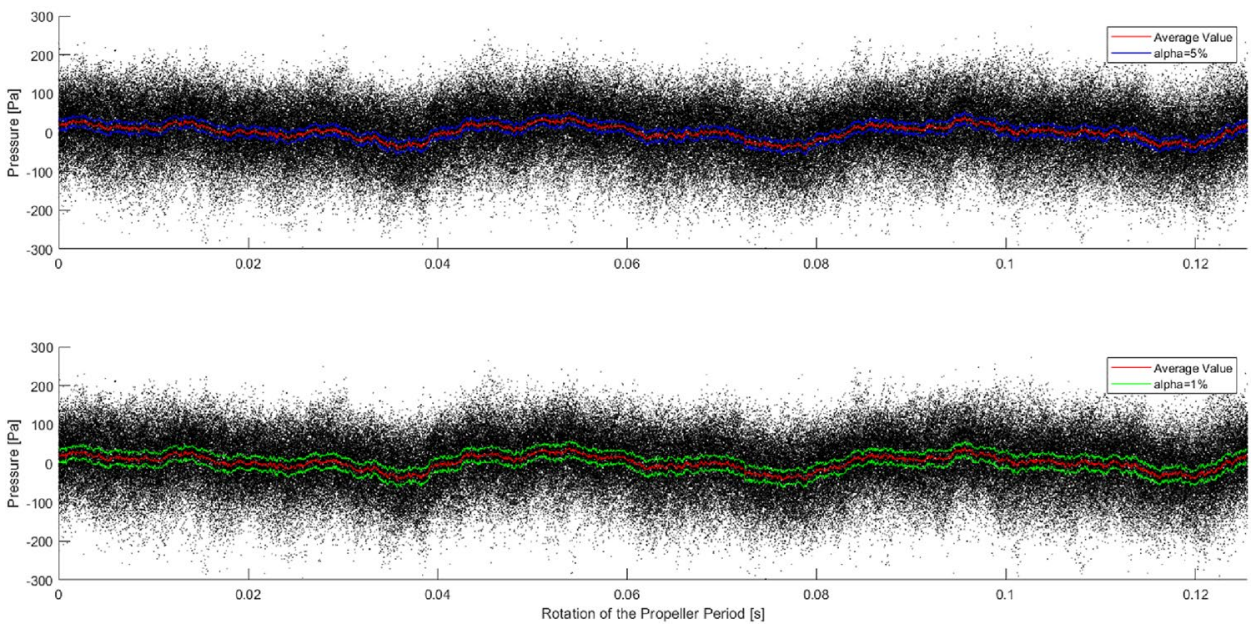
intervals relate to probabilities of $95 \%$ (green line) and 99\% (blue line), respectively. The microphones examined are 6 and 10 for the three different flight conditions I, V, IX.

\section{Conclusions}

Since the tiltrotor is a really peculiar aircraft from the operational point of view, there are few tiltrotor manufacturers in the world. To validate noise prediction tools and to acquire knowledge about the vibroacoustic behaviour of a tiltrotor, a flight test campaign on the AW609 to acquire the acoustic loads acting on the fuselage and the level of noise and internal vibrations. The main purpose of the presented work is to become able to operate to achieve satisfactory levels of comfort for NGCTR passengers. The data acquired has been processed using DNA-an in-house Data Noise Analyzer tool. Among the most interesting results there are the OASPLs from which you can see clearly how the noise levels increase with increasing flight speed and have maximum values in correspondence with the plane of the propeller. The noise spectra are dominated by tones at low frequencies (up to about $400 \mathrm{~Hz}$ ) due to the passage of the propeller blades while at higher frequencies the contribution of the TBL is predominant. This trend is very clear due to the measurements that come from microphones placed toward the tail of the tiltrotor downstream of the wing. Comparisons between internal and external pressure sensors were made to evaluate the noise reduction due to the fuselage and the soundproofing material. Moreover, statistical considerations on the measurements help to provide a confidence interval as the time data presented a high level of dispersion.

Funding Open Access funding provided by Università degli Studi di Napoli Federico II.

Open Access This article is licensed under a Creative Commons Attribution 4.0 International License, which permits use, sharing, adaptation, distribution and reproduction in any medium or format, as long as you give appropriate credit to the original author(s) and the source, provide a link to the Creative Commons licence, and indicate if changes were made. The images or other third party material in this article are included in the article's Creative Commons licence, unless indicated otherwise in a credit line to the material. If material is not included in the article's Creative Commons licence and your intended use is not permitted by statutory regulation or exceeds the permitted use, you will need to obtain permission directly from the copyright holder. To view a copy of this licence, visit http://creativecommons.org/licenses/by/4.0/.
2. Beranek, L.L.: Noise and vibration control. McGraw-Hill Book Co., Inc., c., (1971)

3. Wilby, J.F.: Propeller aircraft interior noise, propeller performance and noise, Vol.2, VKI-LS-1982-08-VOL-2, Von Karman Inst. for Fluid Dynamics (1982)

4. Van Dyke, J.D., Jr., Schendel, J. W., Gunderson, C. O., and Ballard, M. : R: Cabin noise reduction in the DC-9. AIAA Paper No. 67-401, (1967)

5. Wilby, J.F., McDaniel, C.D., Wilby, E.G.: In-flight acoustic measurements on a light twin-engined turboprop airplane, NASA CR-178004, (1985)

6. Magliozzi, B.: Acoustic pressures on a prop-fan aircraft fuselage surface (1980)

7. Petrone, G., Melillo, G., Laudiero, A., De Rosa, S.: A statistical energy analysis (SEA) model of a fuselage section for the prediction of the internal Sound Pressure Level (SPL) at cruise flight conditions. Aerospace Science and Technology (2019)

8. Marulo, F., Sollo, A., Aversano, M., Russo, G., Polito, T.: Interior noise sources identifications, in-flight measurements and numerical correlations of an advanced business aircraft. In: 12th AIAA/ CEAS Aeroacoustics Conference (27th AIAA Aeroacoustics Conference) Cambridge, Massachusetts (2006)

9. Hayden, R.E., Murray, B.S., Theobald, M.A.: A study of interior noise levels, noise sources and transmission paths in light aircraft. NASA CR-I72152 (1983)

10. Wilby, J.F., Gloyna, F.L.: Vibration measurements of an airplane fuselage structure: I. Turbulent boundary layer excitation. J. Sound Vib. 23(4), 443-466 (1972)

11. Karen, H.: Lyle: XV-15 structural acoustic data, NASA technical memorandum 112855. U.S. Army Research Laboratory Technical Report 1423. Langley Research Center, Virginia (1997)

12. Barton, C.Kearney, Mixson, John S.: Characteristics of Propeller Noise on an Aircraft Fuselage. J. Aircr. 18(3), 200-205 (1981)

13. Wilby, J.F., Wilby, E.G.: Analysis of in-flight acoustic data for a twin-engined turboprop airplane, NASA CR-178389 (1988)

14. Howlett, J.T., Schoenster, J.A.: An experimental study of propeller-induced structural vibration and interior noise. SAE Paper 790625 (1979)

15. Bendat, J.S., Piersol, A.G.: Random data: analysis and measurement procedures, 4th edn. Wiley, Hoboken (2010)

16. Signal processing toolbox ${ }^{\mathrm{TM}}$. User's guide. MathWorks (2019)

17. John, W.L.: Digital signal processing using MATLAB for students and researchers, University of Southern Queensland. Wiley (2011) ISBN: 978-0-470-88091-3

18. Braun, S.: discover signal processing: an interactive guide for engineers. Wiley, Hoboken (2008). ISBN: 978-0-470-51970-7

19. Giannakopoulos, Theodoros, Pikrakis, Aggelos: Introduction to audio analysis: A MATLAB approach. Elsevier, Amsterdam (2014). ISBN: 978-0-08-099388-1

20. Vinay, K.I., John G.Pr.: Digital signal processing using MATLAB ${ }^{\circledR}$, Third Edition. Cl-Engineering (2006) ISBN: 978-1-111-42737-5

21. Heumann, C., Schomaker, M.: Shalabh: introduction to statistics and data analysis: with exercises. solutions and applications in $\mathrm{r}$. Springer Nature, Berlin (2017). ISBN: 978-3-319-46160-1

Publisher's Note Springer Nature remains neutral with regard to jurisdictional claims in published maps and institutional affiliations.

\section{References}

1. CS2, Clean Sky 2 Joint undertaking third amended bi-annual work plan and budget (2018-2019) 